\title{
EDITH STEIN E MARTIN HEIDEGGER: DOIS ITINERÁRIOS DE PESQUISA ANTITÉTICOS
}

\author{
Edith Stein and Martin Heidegger: two paths of antithetic research
}

Francesco Alfieri OFM *

Resumo: Ao examinar a abordagem que Heidegger adotou para o desenvolvimento de suas questões a partir de Ser e tempo, Edith Stein sente a necessidade de esclarecer os resultados alcançados pelo pensador nessa obra, o que a leva a incluir um Apêndice em Ser finito e eterno. Neste trabalho, examinaremos a análise steiniana relativa a certas articulações teóricas presentes em Ser e tempo, procurando mostrar que algumas questões levantadas por Stein tornam difícil um confronto do seu pensamento com a posição heideggeriana, uma vez que, em Heidegger, observamos uma "virada radical" em relação à tradicional fenomenologia husserliana. As duas perspectivas de investigação acabam por se mostrar antitéticas em razão das diferentes abordagens das quais partem os seus percursos de pesquisa.

Palavras-chave: Edith Stein. Martin Heidegger. Ser humano. Ser-aí. Acontecimento.

Abstract: In examining the approach adopted by Martin Heidegger to develop his questions from Being and Time, Edith Stein feels the need to clarify the results achieved by the thinker in this particular work. This leads her to include an Appendix in Finite and Eternal Being. The present work aims to examine the Steinian analysis concerning certain theoretical articulations of Being and Time to show that some questions raised by Stein make a confrontation of her thought

\footnotetext{
* Doutor em Filosofia pela Pontificia Università Lateranense, Roma, Itália e professor de Fenomenologia da Religião na mesma Universidade. Artigo recebido em 27/04/2017 e aprovado para publicação em 06/09/2017.
} 
with the Heideggerian position difficult. In Heidegger, we observe a "radical turn" with regard to traditional Husserlian phenomenology. The two research perspectives turn out to be antithetical because of the different approaches their research paths are based on.

Keywords: Edith Stein. Martin Heidegger. Human being. Being-there. Event.

\section{Considerações iniciais}

$\mathrm{N}$ o caminho que iremos percorrer, é necessário deter-se, primeiramente, sobre alguns pontos cruciais que mostram o distanciamento que Heidegger tomou do método fenomenológico husserliano fazendo com que seu pensamento assumisse uma abordagem completamente autônoma. Esse distanciamento, já visível em Ser e tempo (1927), torna-se mais evidente na "virada" (Kehre) radical apresentada na obra Contribuições à filosofia: do acontecimento apropriador (1936). Apenas após o esclarecimento desses pontos, poderemos contextualizar com mais consistência a posição steiniana relativa ao "primeiro Heidegger" do modo como é apresentada pela própria pensadora no apêndice da sua obra Ser finito e eterno, explicitando que a posição de Edith Stein somente pode ser compreendida se for considerada a reorientação advinda do movimento do sentido do ser (Seyn). Analisar a gênese dessa reorientação constituirá a base a partir da qual será possível situar melhor a releitura steiniana de Ser e tempo, permitindo observar que essa releitura não está isenta de alguns "filtros" interpretativos.

\section{Ser e tempo: um caminho para além de Husserl}

Com a publicação de Investigações lógicas (1900-1901), Husserl inaugura uma nova fase para a filosofia contemporânea, por muito tempo presa ao psicologismo e ao estruturalismo positivista, nos quais a visão do mundo permanecia enredada em elaborações que reduziam cada vez mais o material observado a um mero elemento quantificável: um tipo de abordagem que levava as ciências exatas a perderem o sentido de tudo o que pretendiam analisar. Faltava, portanto, a boa parte dessas investigações um novo e rigoroso método que permitisse examinar a questão do sentido e seu fundamento. As bases para alcançar esse método começaram a ser apresentadas em Investigações lógicas, obra na qual, de um lado, Husserl estabelece a prioridade do fenômeno em relação ao observador e, de outro, garante que o ato cognoscitivo, realizado por meio da experiência em primeira pessoa, não seja "contaminado" por nenhuma pré-compreensão do mundo. O fenômeno se manifesta ao observador e o conduz, por meio de reiterados processos inerentes ao próprio ato 
cognoscitivo, à apreensão de sua unidade de sentido. O método husserliano abre, assim, uma nova visão do mundo atraindo a atenção de muitos estudiosos, entre os quais, Max Scheler, Hedwig Conrad-Martius, Edith Stein, Gerda Walther e Martin Heidegger.

A obra Investigações lógicas representa, assim, um ponto de conexão na fenomenologia nascente, a partir do qual é possível repensar o âmbito de investigação e a nova finalidade a ser alcançada pela filosofia. O Círculo Fenomenológico de Gotinga surge justamente a partir das novas diretrizes esboçadas por Husserl nessa obra, consistindo em uma escola concebida como forja do pensar, na qual todos os seus membros - ainda que depois alguns deles se distanciem do projeto husserliano - seriam sempre devedores ao professor. Com suas novas perspectivas, Husserl deu à filosofia um considerável alento direcionando a investigação para um mundo que se abre em sua datidade a quem estiver disposto a acolhê-lo sem sobreposições pré-categoriais.

Heidegger exprime o seu débito para com o professor nas linhas programáticas de Ser e tempo: "As seguintes investigações são possíveis somente graças às bases lançadas por E. Husserl, que trouxe avanços para a Fenomenologia com sua obra Investigações lógicas."

Se as Investigações lógicas constituem o polo de conexão para todos aqueles que se enveredaram pela fenomenologia nascente, será a passagem de Husserl à "virada transcendental" que marcará a decisão de alguns discípulos de se distanciarem do percurso do professor, como ocorreu com Heidegger e Conrad-Martius. Entre aqueles que permaneceram ligados ao método husserliano, alguns ampliaram a investigação para o campo da metafísica tradicional; esse foi o caso de Edith Stein. ${ }^{2}$ Não obstante as diversas interpretações e releituras do método husserliano que, com

\footnotetext{
${ }^{1}$ HEIDEGGER, Sein und Zeit, 1977, § 7: Die phänomenologische Methode der Untersuchung, p. 51. E um pouco mais adiante no § 8: Der Aufriß der Abhandlung (O esboço do tratado), acrescenta em nota: "Se a seguinte investigação der mais alguns passos em direção da exploração das 'coisas mesmas', agradece o autor, principalmente a E. Husserl, por tê-lo familiarizado com as mais variadas áreas da pesquisa fenomenológica, durante seus anos letivos em Friburgo por meio de intensa orientação pessoal e da permissão de pleno acesso às suas investigações não publicadas". («Wenn die folgende Untersuchung einige Schritte vorwärts geht in der Erschließung der "Sachen selbst", so dankt das der Verf. in erster Linie E. Husserl, der den Verf. während seiner Freiburger Lehrjahre durch eindringliche persönliche Leitung und durch freieste Überlassung unveröffentlichter Untersuchungen mit den verschiedensten Gebieten der phänomenologischen Forschung vertraut machte.» (HEIDEGGER, 1977, p. 52, nota 2).

${ }^{2}$ Para uma discussão mais aprofundada da questão, tomo a liberdade de indicar o meu texto: ALFIERI, F. Il serrato confronto con la fenomenologia husserliana in Potenza e atto di Edith Stein: al limite della fenomenologia tradizionale. In: ALES BELLO, A.; ALFIERI, F. (orgs.), Edmund Husserl e Edith Stein: due filosofi in dialogo (Filosofia, 62). Brescia: Morcelliana, 2015, p. 41-99. Trad. portuguesa: Nos limites da fenomenologia tradicional: o cerrado confronto com a fenomenologia husserliana em Potência e ato de Edith Stein, de C. F. Tricarico, Teologia em Questão 30 (2016), p. 125-196.
} 
o passar do tempo, levaram à dissolução do Círculo Fenomenológico de Gotinga, permanece o fato de que o percurso realizado por Heidegger é completamente autônomo, não tendo sido afetado por todas as discussões e incompreensões que se criaram entre o professor e os demais expoentes do Círculo, sobretudo aqueles provenientes da escola de Munique, como por exemplo, Conrad-Martius e Pfänder.

Com efeito, as divergências entre Husserl e Heidegger tiveram início muito antes da publicação de Ser e tempo em 1927. É o que reporta Husserl em uma carta de 1921 enviada ao filósofo polonês Roman Ingarden:

Nesse ínterim, eu avancei muito, e mesmo não negando Ideias I (somente alguns aspectos não estão em conformidade com os meus manuscritos), levei avante os aspectos sistemáticos e aperfeiçoei muitos pontos, sobretudo, de princípio. Agora estou muito seguro. Deus me ajudará a prosseguir. Heidegger também continuou a desenvolver o seu pensamento peculiar e exerce uma forte influência. Qualquer coisa que ele faça, é sempre de altíssima qualidade. ${ }^{3}$

Heidegger traça um percurso de pesquisa que subverte completamente os termos da questão, não apenas frustrando as expectativas de Husserl, mas principalmente decretando ultrapassado o filosofar em termos tradicionais. Podemos dizer que 1927 marca a ruptura com um modo de se conceber a filosofia que também sanciona a sua falência. É preciso ressaltar que, para os dois filósofos, o sentido originário da filosofia parte de posições opostas: se, para Husserl, o télos é identificado pela filosofia também em seus "erros", para Heidegger, é a filosofia mesma que errou contribuindo, assim, para ofuscar o fundamento que deveria se manifestar plenamente: o deixar falar o ser. No que errou a filosofia? Além disso, o filósofo seria capaz de responder às questões de sentido da humanidade? Se essas duas perguntas de fundo tinham levado Husserl a operar uma verdadeira reforma da filosofia a ser implementada com chave fenomenológica, para Heidegger, não era suficiente uma objetivação do mundo fenomênico filtrado pelos limites cognoscitivos do ser humano, dado que o que ele tenta objetivar não é por si objetivável de nenhum modo; a questão do ser (Seinsfrage) constitui, assim, uma autêntica revolução copernicana que não pode ser confiada à filosofia tradicional, ao menos não na forma em que ela operava. Repensar a filosofia ocidental a partir da questão do ser dá a possibilidade a Heidegger de "projetar" uma nova existência para o ser humano que, absorvido por uma profunda inquietude, torna-se cada vez mais elementar, não obstante a técnica crie a ilusão de emancipá-lo por meio da falsa construção de um mundo sempre mais intricado e complexo.

\footnotetext{
${ }^{3}$ HUSSERL, E. Briefe an Roman Ingarden: Mit Erläuterungen und Erinnerungen an Husserl (Phaenomenologica, 25), 1968, p. 23-24 (Carta de 24 de dezembro de 1921).
} 
Ao desenvolvimento da técnica se contrapõe uma desorientação cada vez maior do ser humano.

Com a publicação de Ser e tempo, é dado um novo início para a filosofia do século $\mathrm{XX}$ o que, para Heidegger, consiste em deixar para trás todas as tentativas empreendidas pelas diversas filosofias que, a seu ver, além de terem falhado em suas intenções, nivelaram-se por uma visão de mundo muito objetual, reduzida às categorias ônticas, sacrificando a pesquisa autêntica do fundamento que as sustenta. Ademais, Heidegger entende que também a linguagem por elas adotada é destituída da plenitude capaz de restituir a necessidade de um "novo questionar" - precisamente o sentido do ser - considerado, por muitos, o mais geral de todos (allgemeinste), indefinível (undefinierbar), ou, pior ainda, óbvio (selbstverständliche). ${ }^{4}$ Perdeu-se a necessidade de questionar sobre um tema tão fundamental, porque a submissão do ser humano à mundanidade o conduziu gradualmente a esquecer que é justamente a pesquisa sobre o sentido do ser o que determina o nosso ser no mundo e suas relações. A questão sobre o sentido do ser, porém, precisa ser acolhida por um interlocutor: esse interlocutor é o ser-aí (Dasein) inserido em uma temporalidade. O ser-aí não indica a simples existência nem pode ser rotulado com categorias antropológicas e é apenas voltando-se para a questão do ser que ele pode assumir essa árdua tarefa. Somente quando as categorias ônticas são compreendidas à luz das categorias ontológicas é possível realizar o projeto heideggeriano, que não tem nenhuma relação com a filosofia da existência. Esse rótulo, aplicado por muitos intérpretes à obra Ser e tempo, levará Heidegger a não retomar a segunda parte dessa obra: o pensador percebe que inúmeros equívocos haviam sido gerados em torno da concepção de ser-aí. Na verdade, o próprio Heidegger se deu conta de que o ser-aí não era suficiente para um questionamento autêntico; nas últimas passagens de Ser e tempo, ele observou que a questão sobre o sentido do ser estava "mal colocada". Heidegger sentiu, então, a necessidade de repensar o problema do sentido do ser, não mais por meio da centralidade do ser-aí em sua autoprojeção, mas a partir da dimensão do acontecimento-apropriação (Ereignis) - uma dimensão subtraída do ser-aí - que marcará a "virada" decisiva para o percurso histórico-ontológico a partir de 1936: "Como em suma é possível a compreensão reveladora do ser ao modo do ser-aí? A pergunta pode obter sua resposta no retorno à constituição de ser originária do ser-aí que entende o ser?" 5

\footnotetext{
${ }^{4}$ Cf. HEIDEGGER, 1977, § 1: Die Notwendigkeit einer ausdrücklichen Wiederholung der Frage nach dem Sein, p. 4-6.

${ }^{5}$ «Wie ist erschließendes Verstehen von Sein daseinsmäßig überhaupt möglich? Kann die Frage ihre Antwort im Rückgang auf die ursprüngliche Seinsverfassung des Sein-verstehenden Daseins gewinnen?» (HEIDEGGER, 1977, § 83: Die existenzial-zeitliche Analytik des Daseins und die fundamentalontologische Frage nach dem Sinn von Sein überhaupt, p. 577).
} 
O pensamento heideggeriano em seu estágio mais maduro tem ainda a capacidade de projetar-se adiante e chegar ao nosso tempo, prevendo o risco da instrumentalização política do saber e os seus desvios - risco do qual o percurso teórico heideggeriano também não permaneceu imune em razão de inumeráveis mal-entendidos gerados por seus intérpretes. A deturpação da filosofia se dá com a utilização político-instrumental daquilo que hoje, como então, foi considerado por muitos "filosofia", mas na realidade acaba por ser uma "filosofia circunstancial". O pensador deve operar uma transição (Übergang) no quadro da história do ser: uma passagem especulativa, própria de Heidegger, da (i) questão do ser do primeiro início (Der erste Anfang), ser como enticidade do ente, à (ii) questão do ser do outro início (anderen Anfang), ser como verdade (Wahrheit) ou clareira (Gelichtete) ou desvelamento (Unverborgenheit) ou abertura (Offenheit) do ser e a apresentação dessa verdade do ser como acontecimento-apropriação.

Hoje, na fase culminante da história do primeiro início, ou seja, dos primórdios da metafísica, quem quiser pensar de modo autêntico deve retomar a história do primeiro início e o seu patrimônio conceitual de modo a recuperar o não-dito e não-pensado-a-fundo. Se adequadamente desenvolvido, isso permitirá dar uma nova direção, à história do outro início, na qual se torna central a questão sobre a verdade do ser como acontecimento-apropriação. Em tal percurso, a prioridade é dada ao ser e o pensador poderá aproveitar a oportunidade do outro início apenas se deixar o ser falar. Heidegger não pode confiar esse percurso à simples subjetividade do modo como foi constitutivamente elaborada por Husserl em sua fenomenologia. $\mathrm{O}$ retorno às origens não pode valer-se da intencionalidade husserliana; deve percorrer um caminho no qual seja possível recuperar o nosso originário copertencimento ao ser. Para Heidegger, como mencionamos acima, outros caminhos falharam em seus intentos e a própria filosofia errou quando manteve oculto justamente aquilo que deveria ser trazido à luz. A filosofia, portanto, falhou quando se esqueceu de priorizar a questão fundamental: "Como é essencialmente o ser?" Daqui resulta que, em Heidegger, a prioridade do ser torna-se uma necessidade que nunca poderá ser apreendida das categorias tradicionais que tomam como base o ser humano obscurecido pelo seu próprio isolamento; um isolamento no qual foi enredado pelos erros de uma longa tradição filosófica, criando um antropologismo cada vez mais refinado.

Além disso, a atitude de Heidegger se contrapõe a quem observa do exterior esse pensamento preparatório que tenta fazer a passagem: por muitos, é visto como mera retomada do patrimônio, ou como superação do passado, ou ainda como uma perspectiva arbitrária do futuro, o qual, porém, não é entendido em sua essência por quem o considera desse modo. Para Heidegger, o futuro não é aquilo que vem depois do presente e que pode ser previsto e programado com base em cálculos, mas a capacidade do ser de assumir a responsabilidade, no momento (Augenblick) da doação, sempre imprevisível. 


\section{Ser e tempo: a tomada de posição de Edith Stein}

De 1935 a 1937, Edith Stein redige o seu trabalho mais importante, uma verdadeira obra-prima filosófica intitulada Ser finito e eterno: tentativa de ascensão ao sentido do ser (Endliches und ewiges Sein: Versuch eines Aufstiegs zum Sinn des Seins). É importante destacar que o manuscrito compreendia também dois Apêndices, o primeiro dos quais intitulado "Martin Heidegger: filosofia da existência" ("Martin Heidegger: Existenzphilosophie"). O manuscrito foi confiado ao editor Borgmeyer (Breslávia), que o subdividiu em dois volumes, o segundo dos quais continha o Apêndice sobre Martin Heidegger. Em 1938, as provas já estavam prontas (uma cópia foi conservada no Edith Stein Archiv de Colônia), mas infelizmente os trabalhos foram interrompidos em razão da situação política cada vez mais hostil em relação aos judeus, sobretudo após os acontecimentos de 11 de novembro de 1938. Posteriormente, a obra foi publicada na década de 1950 sem os dois Apêndices, e mesmo as edições posteriores continuaram a não incluí-los ; somente na nova edição, Edith Stein Gesamtausgabe , a obra foi editada em um único volume, considerando seu projeto global ${ }^{8}$. Não é fácil entender qual teria sido o real motivo pelo qual os primeiros editores não puderam (ou quiseram) incluir os Apêndices, mas esse fator é secundário. Com efeito, é necessário deter-se sobre uma questão mais relevante: por que Edith Stein incluiu no fim de Ser finito e eterno um Apêndice sobre Martin Heidegger?

A questão do ser-aí inserido em sua temporalidade - dado que o ser deve ser compreendido a partir do tempo - permanece um problema que Stein tem a intenção de esclarecer em relação ao projeto de Ser finito e eterno. Destacaremos, agora, algumas citações dessa obra que mostram articulações teóricas correspondentes a pontos de ruptura do modo como são formulados por Stein em sua análise de Ser e tempo:

1. São evitadas as expressões "eu", "sujeito", "alma", "pessoa", bem como "ser humano" e "vida", porque elas representam uma objetivação do ser-aí - considera-se que esse seja o erro da ontologia antiga e da dogmática cristã, dado que elas reduziram o ser-aí às categorias da simples presença; ${ }^{9}$

\footnotetext{
${ }^{6}$ Cf. STEIN, Endliches und ewiges Sein: Versuch eines Aufstiegs zum Sinn des Seins, 1950, $1962^{2}, 1986^{3}$.

${ }^{7}$ STEIN, Endliches und ewiges Sein: Versuch eines Aufstiegs zum Sinn des Seins, Anhang: Martin Heideggers Existenzphilosophie - Die Seelenburg, eingeführt und bearbeitet, 2006.

${ }^{8}$ Cf. STEIN, 2006, p. 445-499.

9 STEIN, 2006, p. 447: «Die Ausdrücke „Ich“, „Subjekt“, „Seele“, „Person“, ebenso „Mensch“ und „Leben“ werden vermieden, weil sie entweder eine Verdinglichung des Daseins bedeuteten - es wird als der Fehler der antiken Ontologie und der christlichen Dogmatik bezeichnet, daß sie das Dasein unter die Kategorien des Vorhandenen rückten - [...]».
} 
2. “O si-mesmo (Selbst) é, porém, em primeiro lugar e principalmente, um inautêntico Man-selbst $t^{10}$. [...] A cotidianidade média do ser-aí pode, portanto, ser determinada como o ser-no-mundo decaído-aberto e lançado-que se lança, a partir do qual, no seu ser no mundo e no ser com os outros, dirige-se por si mesmo ao seu poder-ser mais próprio" (passagem de Ser e tempo citada em Ser finito e eterno); ${ }^{11}$

3. As verdade eternas poderiam dar-se apenas se existisse um ser-aí eterno, e apenas se este último fosse demonstrado, elas seriam comprovadas; ${ }^{12}$

4. De Deus, fala-se apenas ocasionalmente em notas marginais de modo a excluí-lo; o ser divino, que poderia esclarecer o sentido do ser, permanece totalmente fora de discussão; ${ }^{13}$

5. O que é a morte? Heidegger responde: o fim do ser-aí. Ele acrescenta rapidamente que com isso não se deve tomar nenhuma decisão quanto à possibilidade de uma vida após a morte. [...] permanece realmente aberta a possibilidade de uma vida após a morte, se esta é interpretada como o fim do ser-aí?; ${ }^{14}$

6. O próprio Heidegger fala da interpretação do tempo como "imagem da eternidade", mas somente para excluí-la; ${ }^{15}$

7. Em suas análises, não há espaço para aquilo que dá plenitude ao ser humano: alegria, felicidade, amor;'16

8. O ser "cotidiano" é apresentado de modo ambíguo, porque sugere o equívoco <de se pensar> que a vida social como tal seja uma condição de "decadência", e o ser autêntico seja sinônimo de ser

\footnotetext{
${ }^{10}$ [A expressão Man-selbst é de difícil tradução. O man, referente ao "si" que em português indicaria a indeterminação do sujeito ("se"), deve ser aqui entendido como um "si inautêntico" de caráter impessoal. N. da T.]

${ }^{11}$ HEIDEGGER, Sein und Zeit. Halle a. d. S., 1927, p. 181, citado por STEIN, 2006, p. 450-451: « „Das Selbst aber ist zunächst und zumeist uneigentlich das Man-selbst. [...] Die durchschnittliche Alltäglichkeit des Daseins kann demnach bestimmt werder als das verfallend-erschlossene, geworfenentwerfende In-der-Welt-sein, dem es in seinem Sein bei der Welt und in Mitsein mit Anderen um das eigenste Seinkönnen selbst geht" ». Edith Stein cita uma passagem de Ser e tempo, publicada inicialmente no Jahrbuch für Philosophie und Phänomenologische Forschung, Band VIII. Halle: Max Niemeyer, 1927, p. 181.

12 STEIN, 2006, p. 452: «Ewige Wahrheiten könnte es nur geben, wenn ein ewiges Dasein wäre, und nur wenn es nachgewiesen wäre, wären sie erwiesen».

${ }^{13}$ STEIN, 2006, p. 463: «Von Gott ist nur gelegentlich in Randbemerkungen und in ausschlieBender Weise die Rede: das göttliche Sein als etwas, was für die Klärung des Sinnes von Sein überhaupt Bedeutung haben könnte, bleibt völlig ausgeschaltet».

${ }^{14}$ STEIN, 2006, p. 471-472: «Was ist der Tod? Heidegger antwortet: Das Ende des Dasein. Er fügt sofort hinzu, es solle damit über die Möglichkeit eines Lebens nach dem Tode keine Entscheidung gefällt sein. [...] bleibt wirklich die Möglichkeit eines Lebens nach dem Tode offen, wenn man ihn als Ende des Daseins deutet?».

15 STEIN, 2006, p. 477: «Heidegger spricht selbst von der Zeit als „Abbild der Ewigkeit", aber nur, um sie auszuschließen».

${ }^{16}$ STEIN, 2006, p. 479: «[...] in seinen Untersuchungen kein Raum ist für das, was dem menschlichen Sein Fülle gibt: Freude, Glück, Liebe».
} 
solitário, enquanto, no lugar disso, tanto a vida solitária quanto a comunitária têm, cada uma delas, uma forma autêntica e uma forma de decadência, ${ }^{17}$

É nossa intenção deter-nos sobre esses oito pontos de ruptura, porque eles nos mostram as interpretações de Stein sobre Ser e tempo e o que está em jogo nessa controvérsia, embora deva ser salientado que a pensadora, em seu Apêndice, analisa também algumas considerações levantadas por Conrad-Martius - compartilhando do seu pensamento -, além de examinar rapidamente outras três publicações posteriores à obra de 1927: Kant e $o$ problema da metafísica (Kant und das Problem der Metaphysik, 1929); Sobre a essência do fundamento (Vom Wesen des Grundes, 1929) e, por último, a aula inaugural que Heidegger realizou em 24 de julho de 1929 na Universidade de Friburgo, O que é metafísica? (Was ist Metaphysik?).

Stein se insere na corrente de pensadores que sentiram a necessidade de se confrontar com Ser e tempo e, mesmo compartilhando da estrutura de base da obra acerca da questão do ser - ou melhor acerca do sentido (Sinn) do ser -, critica o percurso que Heidegger adotou para resolver essa questão fundamental. Uma interpretação precipitada pode supor que as suas críticas ao ser-aí - à temporalidade do ser-aí (Zeitlichkeit), à cotidianidade (Alltäglichkeit) que conota o modo de ser no qual o ser-aí tende a abandonar-se às modalidades mais óbvias, comuns a todos, e portanto, inautênticas (uneigentlich) - consistam simplesmente nos pontos de não confluência, ou seja, aqueles que não se conciliam com o itinerário empreendido pela pensadora quando tenta justificar a abertura natural e a tensão que o ser finito tem em direção ao Ser eterno; se observarmos o subtítulo de sua obra, apreenderemos a finalidade que a filósofa pretende alcançar: "tentativa de ascensão ao sentido do ser" (Versuch eines Aufstiegs zum Sinn des Seins). No entanto, todas as problemáticas reunidas nos oitos pontos acima têm um contexto ainda mais complexo: os novos termos cunhados por Heidegger - para os quais Stein chama a atenção nas primeiras passagens do seu Apêndice ${ }^{18}$ - consistiam e continuarão consistindo na principal dificuldade para todos aqueles que pretendem se enveredar pelo percurso heideggeriano. Fazer uma leitura das categorias heideggerianas - como por exemplo comunidade (Gemeinschaft) e ser-com-outros (Mitsein mit Anderen) ${ }^{19}$ - com chave fenomenológica, em sua

\footnotetext{
${ }^{17}$ STEIN, 2006, p. 480-481: «Das "alltägliche“ Sein ist zweideutig dargestellt, weil es das Mißverständnis mindestens nahelegt, als sei Gemeinschaftsleben als solches „verfallen“, und eigentliches Sein gleichbedeutend mit einsamen Sein, während doch sowohl einsames als Gemeinschaftsleben ihre eigentliche und ihre Verfallsform haben».

${ }^{18}$ Cf. STEIN, 2006, p. 445.

${ }^{19}$ Apenas com base nessa diferença, é possível entrever que em Heidegger o Mitsein não tem nenhum significado antropológico. Trata-se de polos opostos, nos quais cada confronto empobrece o dinamismo das diferentes abordagens tomadas em sua singularidade.
} 
acepção tradicional, conduz certamente a equívocos. O projeto heideggeriano subverte completamente as categorias utilizadas anteriormente pela filosofia, incluindo a bagagem adquirida na escola de Husserl. As duas modalidades segundo as quais o ser-aí exerce o seu poder ser autenticidade (Eingentlichkeit) e inautenticidade (Uneigentlichkeit) - são um exemplo disso. Essa terminologia não é equivalente àquela empregada por Husserl em sua ontologia formal - independência (Selbständigkeit) e não-independência (Unselbständigkeit) -, que Stein retomará em suas investigações em Potência e ato. O ser-aí e o seu modo de ser no duplo aspecto de autenticidade/inautenticidade não é compatível com as investigações sobre o ser humano do modo como Stein as conduz em seu percurso filosófico. Estamos diante de um novo construto, o heideggeriano. O ser-aí apropria-se de uma existência apenas se for orientado para a questão do sentido do ser, colocando- $a$ na temporalidade na qual o instante (Augenblick) é a única realização autêntica do presente. Caso contrário, resta o ser mundano, o "si" (Man) impessoal, ou seja, o ser inautêntico que se encontra na cotidianidade: um viver incapaz de projetar e decidir e, portanto, abandonado e submetido ao mundo dos outros. O "si" (Man) indica tudo e ninguém; nessa condição, o ser-aí iguala o seu comportamento ao dos outros até se perder, chegando à total ausência de percepção, não sentindo a mínima necessidade de redespertar.

Esse percurso não tem muita relação com a abordagem steiniana sobre o ser humano, na qual, considerado em sua tripartição - corpo (Körper/Leib), psique (Psyche/Seele), espírito (Geist) -, é inserido em uma temporalidade na qual percebe uma tensão em direção ao Ser infinito. É justamente essa tensão que é difícil encontrar na abordagem heideggeriana. Assim como outros elementos, ela não está presente no construto heideggeriano. Várias são as diferenças encontradas nas duas abordagens como é o caso da noção de instante (Augenblick) de Heidegger - um presente no qual o ser para a morte (Sein zum Tode) determina o ser finito do ser-aí - e o questionamento de Stein justamente com relação a essa noção heideggeriana, no sentido de saber se "permanece aberta a possibilidade de uma vida após a morte". O ser-aí (Dasein) não pode ser equiparado ao ser humano (Mensch). As duas perspectivas seguem percursos diferentes, mas o que podemos supor é que as dúvidas levantadas por Stein poderiam ser solucionadas, em parte, pela "virada" (Kehre) que acontece após a publicação de Ser e tempo: Heidegger percebe que o percurso traçado é insuficiente para colocar a questão do ser. Somente o acontecimento-apropriação, que indica o copertencimento essencial do ser humano à história do ser e do ser à história do ser humano, norteará o caminho de Heidegger a partir de 1936; esse novo percurso permitirá o repassar das diversas épocas históricas com base no contínuo manifestar-se e subtrair-se do ser. $\mathrm{O}$ ser e o seu colocar-se a questão têm um papel ainda mais decisivo no 
segundo Heidegger e indicam, sobremaneira, a distância que essa abordagem toma das investigações steinianas. Com isso não se quer indicar a incompatibilidade dos dois percursos, mas ressaltar que, sem dúvida, uma dificuldade se impõe para quem segue o percurso heideggeriano: é preciso, primeiramente, abandonar toda pretensão de circunscrever, sobrepor, ou pior ainda, subestimar o seu construto linguístico, criado para abrir novos horizontes de sentido. A sua abertura ao arcabouço poético é a prova da contínua busca por uma linguagem capaz de sustentar a fundação de um saber essencial: o recurso a Hölderlin o auxilia a recriar uma nova linguagem.

Para concluir, acredito que seja importante destacar o quanto é difícil hoje até mesmo colocar a questão "O que é o ser?", uma vez que se incutiu no ser humano a impotência de dirigir o olhar para além da fixidade na qual ele se abateu, quando absolutizou e reduziu o mundo ao próprio raio de ação. O ser humano contemporâneo não sente a necessidade de se colocar a questão sobre o ser: não é capaz de sentir essa necessidade porque foi dominado por suas próprias ações e pela certeza de suas representações. E é por essa razão que o ser humano vive no esquecimento do ser. No ato da produção, o ser humano acreditou fazer, por meio da manipulação, um ente a ser dominado; esse fazer, destruiu, então, toda ligação com o ser e, portanto, a possibilidade de alcançar a sua fundação: o acesso à esfera ontológica lhe foi, assim, completamente bloqueado. A fixidade do domínio sobre o ente leva o ser humano a manipulá-lo até criar uma estratégia que destrói silenciosamente a disponibilidade à verdade do ser. Admitir essa derrota seria a oportunidade para reconsiderar as críticas, mais atuais do que nunca, que Heidegger fazia à modernidade e ao domínio mundial da técnica.

\section{Referências Bibliográficas}

ALFIERI, F. Il serrato confronto con la fenomenologia husserliana in Potenza $e$ atto di Edith Stein: al limite della fenomenologia tradizionale. In: ALES BELLO; ALFIERI, F. (orgs.), Edmund Husserl e Edith Stein: due filosofi in dialogo (Filosofia, 62). Brescia: Morcelliana, 2015, p. 41-99; tr. port. Nos limites da fenomenologia tradicional: o cerrado confronto com a fenomenologia husserliana em Potência e ato de Edith Stein, de C. F. Tricarico. Teologia em Questão, 30 (2016), p. 125-196.

HEIDEGGER, M. Sein und Zeit. Frankfurt a. M.: Klostermann, Gesamtausgabe, Bd. 2, Abt. I: Veröffentlichte Schriften 1914-1970, org. F.-W. von Herrmann, 1977. 
HUSSERL, E. Briefe an Roman Ingarden: mit Erläuterungen und Erinnerungen an Husserl. Den Haag: Nijhoff, (Phaenomenologica, 25) org. R. Ingarden, 1968.

STEIN, E. Endliches und ewiges Sein: Versuch eines Aufstiegs zum Sinn des Seins, org. L. Gelber e R. Leuven. Louvain-Freiburg-Basel-Wien: Herder, (ESW, II) 1950, $1962^{2}, 1986^{3}$.

Endliches und ewiges Sein: Versuch eines Aufstiegs zum Sinn des Seins, Anhang: Martin Heideggers Existenzphilosophie - Die Seelenburg, eingeführt und bearbeitet v. A.U. Müller. Freiburg-Basel-Wien: Herder, (ESGA, 11-12), 2006.

Endereço do Autor:

Prof. Dr. Francesco Alfieri

Pontificia Università Lateranense

Piazza San Giovanni in Laterano, 4

00120 - Città del Vaticano

frafrancescoalfieriofm@gmail.com 